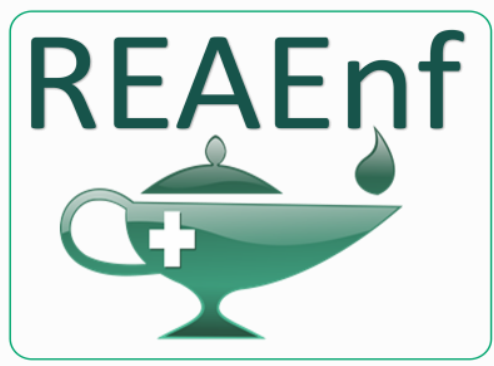

Revista Eletrônica Acervo Enfermagem
REVISÃO BIBLIOGRÁFICA

Recebido em: 12/2019

Aceito em: 1/2020

Publicado em: 4/2020

\title{
Produção científica acerca do assédio moral nas relações de trabalho de enfermagem no Brasil
}

\author{
Scientific production about moral harassment in labor relations in nursing in Brazil \\ Producción científica sobre el acoso moral en las relaciones laborales de enfermería c \\ Brasil
}

Adilson Mendes de Figueiredo Júnior ${ }^{1 *}$, Jéssica de Souza Pereira ${ }^{1}$, João Augusto do Carmo Cardoso ${ }^{1}$, Glaucilene Viana Santa Brígida', Janice de Matos Frazão', Clenilde dos Santos Fernandes ${ }^{1}$, Deisiane do Socorro da Silva Barbosa ${ }^{1}$, Márcia Cristiane Rodrigues da Silva' ${ }^{1}$, Luana Baía Menezes², Ana Rosa Tavares da Paixão³.

\begin{abstract}
Resumo: Esse artigo buscou de identificar as produções científicas acerca do assédio moral nas relações de trabalho de enfermagem no Brasil. Trata-se de uma Revisão Integrativa da Literatura. Optou-se em organizar os resultados de acordo com o título, estado onde foram produzidos, ano de publicação, base de dados onde foram encontrados e formação dos autores. Os artigos demostraram que uma nova dinâmica do trabalho tem sido inserida em um meio de competitividade e dinamismo, onde a produtividade e os lucros acabam por muitas vezes sendo mais valorizados que o bem-estar profissional, o assédio moral ainda é uma violência presente em diversos setores produtivos, inclusive os ambientes que envolvem a saúde. A violência no ambiente laboral é tão antiga quanto à origem do trabalho, mas foi apenas nas últimas décadas que o termo assédio moral começou a ser mais evidente e valorizado no contexto que envolve os trabalhadores nos diversos setores produtivos.
\end{abstract}

Palavras-chave: Enfermagem, Local de trabalho, Assédio não sexual.

\begin{abstract}
This article aims to identify the scientific productions about moral harassment in labor relations in nursing in Brazil. It is an Integrative Literature Review (RIL). The results it was decided to organize the results according to the title of the articles, the state where they were produced, the year of publication, the database where they were found and the authors' education. The new dynamics of work have been inserted in a medium of competitiveness and dynamism, where productivity and profits are often valued more than professional well-being, bullying is still a violence present in many productive sectors, including environments that involve health. Violence in the workplace is as old as the origin of work, but it has only been in recent decades that the term bullying has become more evident and valued in the context involving workers in the various productive sectors.
\end{abstract}

Keywords: Nursing, Job site, Moral harassment.

${ }^{1}$ Escola Superior da Amazônia (ESAMAZ), Belém-PA. *E-mail: adilsonmdfj@hotmail.com

2 Faculdade da Amazônia (FAMAZ), Belém-PA.

3 Universidade Federal do Pará (UFPA), Belém-PA. 
Resumen: Este artículo buscaba identificar las producciones científicas sobre el acoso escolar en las relaciones laborales de enfermería en Brasil. Es una Revisión Integral de la Literatura. Se decidió organizar los resultados de acuerdo con el título de los artículos, el estado donde se produjeron, el año de publicación, la base de datos donde se encontraron y los antecedentes de los autores. La nueva dinámica del trabajo se ha insertado en un medio de competitividad y dinamismo, donde la productividad y las ganancias a menudo se valoran más que el bienestar profesional, el acoso escolar sigue siendo una violencia presente en muchos sectores productivos, incluidos ambientes que involucran salud. La violencia en el lugar de trabajo es tan antigua como el origen del trabajo, pero solo en las últimas décadas el término bullying se ha vuelto más evidente y valorado en el contexto de los trabajadores en los diversos sectores productivos.

Palabras clave: Enfermería, local de Trabajo, Acoso no sexual.

\section{INTRODUÇÃO}

O assédio moral ainda é uma realidade bastante presente nos ambientes de trabalho, tanto na área da saúde como em diversas outras áreas, sempre relacionado a situações de humilhações e constrangimentos. As relações interpessoais nos meios produtivos muitas vezes levam o trabalhador a uma sequência de alterações biológicas, psicológicas e até mesmo comportamentais que muitas vezes interferem na força de trabalho e até mesmo nas relações familiares e interpessoais (BOBROFF MCC e MARTINS JT, 2013).

Sentimentos de impotência, raiva, revolta, decepção, tristeza e humilhação são as diversas reações encontradas em um trabalhador que sofre pelo assédio moral. Muitas vezes esses sentimentos estão associados ao fato de não poderem compartilhar com outras pessoas muitas das situações vividas no ambiente de trabalho o que leva os mesmos a um autoconceito de menos valia, pois muitas vezes são vistos como desinteressados e preguiçosos (SCHLINDWEIN VLDC, 2013).

As relações de trabalho se apresentam como as relações sociais, ou seja, marcadas por competitividade, individualidade, consumismos e falta de respeito ao próximo. Fatores que acabam fazendo parte das justificativas sobre as causas de assédio moral no local de trabalho, mas ter bom desempenho e atingir normas e princípios éticos não é mais garantia de estabilidade no emprego, pois atualmente o mais importante é ultrapassar metas e aumentar produtividade, sem importar muito os caminhos criados para isso (BARRETO M e HELOANI R, 2015).

Relações de trabalho marcadas pela opressão e até mesmo pelo sofrimento fazem parte de uma dinâmica produtiva bem antiga no mundo, mas o termo assédio moral se apresenta como uma expressão bem mais recente que precisa ser cada vez mais entendida e modificada para se evitar adoecimentos físicos e mentais (SILVA OD e RAICHELIS R, 2015). O assédio moral é um fenômeno complexo e real do exercício da enfermagem além de ser um tipo de violência que envolve princípios éticos tanto individuais quanto coletivos limitando a efetivação do trabalho de enfermeiros (as), mesmo o atual cenário laboral sendo marcado por fatores estressantes, o assédio não pode ser considerado como algo dentro da normalidade e necessário dentro dos ambientes de trabalho (BOBROFF MCC e MARTINS JT, 2013).

$O$ assédio moral se configura como uma violência entre um assediador e um assediado e pode ser configurado de forma hierárquica, ou seja, o assediador poder ser um trabalhador superior, do mesmo nível hierárquico e até mesmo por subordinados. A perseguição que caracteriza o assédio coloca o trabalhador em uma situação de medo e vulnerabilidade que mesmo acontecendo de maneira sútil e indireta, podem em longo prazo, causar sérios danos à saúde da vítima (COSTA ICP, et al., 2015). Esse artigo buscou de identificar as produções científicas acerca do assédio moral nas relações de trabalho de enfermagem no Brasil.

\section{MÉTODOS}

Trata-se de uma Revisão Integrativa da Literatura (RIL). O estudo foi desenvolvido com uma abordagem qualitativa descritiva com o objetivo geral de identificar as produções científicas acerca do assédio moral nas relações de trabalho de enfermagem no Brasil. 
Inicialmente foi criada uma questão norteadora para o seguimento do estudo: Quais as produções científicas acerca do assédio moral nas relações de trabalho de enfermagem no Brasil? Após a elaboração da pergunta deu-se início a coleta de dados que perdurou de 4 de Janeiro de 2017 a 15 de Janeiro de 2017

Para a busca bibliográfica utilizou-se como critérios de inclusão artigos científicos completos, produzidos no Brasil e em língua portuguesa, como critério temporal escolheu-se trabalhar com todos os anos presentes na seleção (2006 - 2015) visto que o número de artigos encontrados foi de apenas 17 publicações. Após a eliminação de artigos repetidos a amostra final ficou condensada em um total de 9 publicações.

Figura 1 - Organograma de critérios de inclusão e exclusão.

\section{Revisão Integrativa da Literatura}

Fonte: Júnior AMF, et al., 2017.

\section{Critério Exclusão}

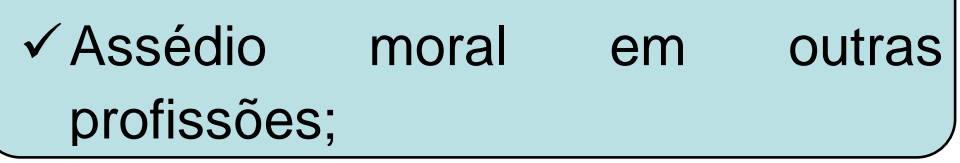

Para seleção dos estudos foi utilizado os seguintes descritores em ciências da saúde (DeCS): Enfermagem AND Local de Trabalho AND Assédio não Sexual. na Biblioteca Virtual da Saúde (BVS), nas bases científicas da Literatura Latino-Americana e do Caribe em Ciências da Saúde (LILACS) e Base de Dados em Enfermagem (BDENF).

Para facilitar a organização do conteúdo dos artigos criou-se um instrumento de coleta de dados baseado no título do trabalho, estado onde foram publicados, ano de publicação, base de dados e formação dos autores.

\section{RESULTADOS E DISCUSSÃO}

Optou-se em organizar os resultados de acordo com o título dos artigos, o estado onde foram produzidos, ano de publicação, base de dados onde foram encontrados e formação dos autores. As produções que envolveram o assédio moral e o trabalho de enfermagem se concentraram basicamente nas regiões nordeste, sudeste e sul, distribuídos nos estados da Paraíba $(44,44 \%)$, do estado do Rio de Janeiro (22,22\%), do estado de São Paulo $(11,11 \%)$, do estado do Maranhão $(11,11 \%)$ e do estado do Paraná $(11,11 \%)$. A maioria dos achados científicos foi publicada nos últimos 05 anos $(66,66 \%)$, mas variaram entre os anos de 2006 e 2015. 
Quadro 1 - Características dos artigos científicos que abordam o assédio moral e o trabalho de enfermagem.

\begin{tabular}{|c|c|c|c|}
\hline Título & Autor & Objetivo & Resultados \\
\hline $\begin{array}{l}\text { Assédio moral no âmbito da } \\
\text { enfermagem: revisão integrativa da } \\
\text { literatura. }\end{array}$ & $\begin{array}{l}\text { SANTOS SIL, et al., } \\
2014 .\end{array}$ & $\begin{array}{l}\text { Sintetizar a produção científica acerca da prática } \\
\text { do assédio moral no âmbito da Enfermagem. }\end{array}$ & $\begin{array}{l}\text { A prevalência da prática do assédio moral na } \\
\text { Enfermagem tem crescido, de forma } \\
\text { significativa, essencialmente entre os } \\
\text { trabalhadores do sexo feminino. }\end{array}$ \\
\hline $\begin{array}{l}\text { Problemas de violência ocupacional } \\
\text { em um serviço de urgência } \\
\text { hospitalar da cidade de londrina, } \\
\text { Paraná, Brasil. }\end{array}$ & $\begin{array}{l}\text { CEZAR ES e } \\
\text { MARZIALE MHP, } \\
2006 .\end{array}$ & $\begin{array}{l}\text { Caracterizar os problemas de violência } \\
\text { ocupacional, detectados pelos trabalhadores das } \\
\text { equipes de enfermagem e médica do Serviço de } \\
\text { Urgência Hospitalar. }\end{array}$ & $\begin{array}{l}\text { As violências sofridas pelos trabalhadores } \\
\text { causaram sentimentos de tristeza, raiva, } \\
\text { irritação, ansiedade e estresse. }\end{array}$ \\
\hline $\begin{array}{l}\text { Violência psicológica no trabalho da } \\
\text { enfermagem. }\end{array}$ & $\begin{array}{l}\text { LIMA GHA e Sousa } \\
\text { SMA, } 2015 .\end{array}$ & $\begin{array}{l}\text { Investigar e caracterizar práticas de violência } \\
\text { psicológica intraequipe, nas relações entre } \\
\text { pacientes, acompanhantes e outros profissionais } \\
\text { com os trabalhadores de enfermagem. }\end{array}$ & $\begin{array}{c}\text { Agressão verbal é o subtipo de violência } \\
\text { psicológica mais frequente } 95 \%(84) \text {, seguida } \\
\text { pelo assédio moral } 27 \%(24) \text {. }\end{array}$ \\
\hline $\begin{array}{l}\text { Situações de assédio moral } \\
\text { vivenciadas por enfermeiros no } \\
\text { ambiente de trabalho. }\end{array}$ & $\begin{array}{l}\text { CAHÚ GRP, et al., } \\
2014 .\end{array}$ & $\begin{array}{l}\text { Investigar situações de assédio moral vivenciadas } \\
\text { por enfermeiros em seu ambiente de trabalho. }\end{array}$ & $\begin{array}{c}\text { A situação de assédio moral mais frequente } \\
\text { diz respeito ao agressor manipular pessoas } \\
\text { para assumir posicionamentos contrários aos } \\
\text { interesses da vítima. }\end{array}$ \\
\hline $\begin{array}{l}\text { Assédio moral na atenção básica } \\
\text { segundo os profissionais de } \\
\text { enfermagem. }\end{array}$ & $\begin{array}{l}\text { ANDRADE CG, et al., } \\
2015 .\end{array}$ & $\begin{array}{c}\text { Investigar como os profissionais de enfermagem } \\
\text { compreendem o assédio moral, bem como } \\
\text { identificar essas situações vivenciadas pelos } \\
\text { profissionais dessa área, suas causas e } \\
\text { consequências para a saúde desses } \\
\text { trabalhadores. }\end{array}$ & $\begin{array}{l}\text { O assédio moral é disseminado entre } \\
\text { enfermeiros e técnicos de enfermagem, } \\
\text { apesar de alguns profissionais discernirem o } \\
\text { conceito dessa prática, sendo notória a } \\
\text { prevalência do tipo descendente. }\end{array}$ \\
\hline
\end{tabular}

REAEnf/EJNC | Vol. 3 | e2742 | DOI: https://doi.org/10.25248/REAenf.e2742.2020 Página 4 de 9 


\begin{tabular}{|c|c|c|c|}
\hline $\begin{array}{c}\text { Assédio moral no trabalho no setor } \\
\text { saúde no rio de janeiro: algumas } \\
\text { características. }\end{array}$ & $\begin{array}{l}\text { XAVIER ACH, et al., } \\
2008 .\end{array}$ & $\begin{array}{l}\text { Analisar a magnitude e algumas características do } \\
\text { fenômeno do assédio moral no trabalho no setor } \\
\text { saúde do Rio de Janeiro. }\end{array}$ & $\begin{array}{c}\text { O grupo profissional que teve maior } \\
\text { proporção de vítimas de assédio moral foi o } \\
\text { de auxiliar de enfermagem }(22,7 \%) \text {. Colegas, } \\
\text { supervisores ou administradores } \\
\text { compuseram o mais importante grupo de } \\
\text { agressores }(48,7 \%) \text {. }\end{array}$ \\
\hline $\begin{array}{l}\text { Assédio moral no trabalho de } \\
\text { enfermagem. }\end{array}$ & $\begin{array}{l}\text { THOFEHRN MB, et } \\
\text { al., } 2008 .\end{array}$ & $\begin{array}{l}\text { Promover uma reflexão teórica sobre o assédio } \\
\text { moral no trabalho da Enfermagem, bem como } \\
\text { impulsionar a valorização da dimensão da } \\
\text { subjetividade do trabalhador. }\end{array}$ & $\begin{array}{l}\text { As principais formas de assédio moral } \\
\text { identificadas na Enfermagem são: } \\
\text { humilhações em público e a portas fechadas, } \\
\text { com ameaças; depreciação da imagem } \\
\text { profissional; boatos e rumores maldosos; } \\
\text { cobranças absurdas por parte das chefias. }\end{array}$ \\
\hline $\begin{array}{l}\text { Assédio moral: compreensão de } \\
\text { estudantes de enfermagem. }\end{array}$ & $\begin{array}{l}\text { GOUVEIA EML, et } \\
\text { al., } 2012 .\end{array}$ & $\begin{array}{l}\text { Investigar como os estudantes de enfermagem } \\
\text { compreendem o assédio moral. }\end{array}$ & $\begin{array}{l}\text { Apesar de o entendimento dos discentes } \\
\text { inseridos no estudo acerca do assédio moral } \\
\text { estar em consonância com a literatura, } \\
\text { apresenta algumas lacunas concernentes às } \\
\text { características definidoras do assédio } \\
\text { relacionadas ao assediador. }\end{array}$ \\
\hline $\begin{array}{l}\text { Tendência dos estudos sobre } \\
\text { assédio moral e trabalhadores de } \\
\text { enfermagem. }\end{array}$ & $\begin{array}{l}\text { FONTES KB, et al., } \\
2011 .\end{array}$ & $\begin{array}{l}\text { Analisar o conhecimento produzido sobre o } \\
\text { assédio moral na enfermagem, apresentado em } \\
\text { publicações nacionais e internacionais. }\end{array}$ & $\begin{array}{l}\text { Resultados dos estudos confirmam a } \\
\text { presença do assédio moral na enfermagem, } \\
\text { contudo, apontam que estes profissionais têm } \\
\text { aceitado e reproduzido este tipo de violência, } \\
\text { evidenciando a necessidade de } \\
\text { conscientização desta população. }\end{array}$ \\
\hline
\end{tabular}

Fonte: Júnior AMF, et al., 2017.

REAEnf/EJNC | Vol. 3 | e2742 | DOI: https://doi.org/10.25248/REAenf.e2742.2020 Página 5 de 9 
A nova dinâmica do trabalho tem sido inserida em um meio de competitividade e dinamismo, onde a produtividade e os lucros acabam por muitas vezes sendo mais valorizados que o bem-estar profissional, o assédio moral ainda é uma violência presente em diversos setores produtivos, inclusive os ambientes que envolvem a saúde (CAHÚ GRP, et al., 2014).

O assédio moral acaba se tornando presente, praticamente, em todos os cenários de força produtiva e, principalmente, na área da saúde onde é possível perceber tal tipo de agressão em todas as profissões e em diversos setores de atenção, ou seja, atenção primária, secundária e terciária, porém, observa-se que as áreas mais dinâmicas, como urgências e Unidades de Tratamento Intensivo (UTI) ainda representam locais com maiores taxas de assédio moral, além de agressões físicas e até sexuais (CAHÚ GRP, et al., 2014).

Os trabalhadores da enfermagem ainda são a maioria entre aqueles que sofrem pelo assédio moral, violência essa que acaba abalando a integridade física e mental de qualquer trabalhador, a enfermagem em sua maioria acaba reunindo características que a tornam uma profissão com uma exposição maior frente a esse tipo de violência, como: a continuidade do atendimento e a alta carga emocional, principalmente por lidar com a morte (SANTOS SIL, et al., 2014).

A violência no trabalho pode ser tanto física quanto psicológica, a forma como esse ato irá afetar e interferir na força produtiva do trabalhador vai depender da intensidade do assédio e das características individuais do indivíduo, em relação à área da saúde, as unidades de urgência e emergência ainda constituem os espaços com maiores relatos de assédios e agressões físicas, psíquicas e morais (CEZAR ES e MARZIALE MHP, 2006).

As unidades de urgência e emergência lidam com o dinamismo na assistência e muitas vezes, tanto profissionais quanto usuários acabam por vez "rompendo" seus limites de tolerância, fato esse, que facilita as relações de assédio. Por se tratar de uma área assistencial representativa de perigo, principalmente, por se associar o tempo com a perspectiva de melhora, a pressa de muitos usuários acaba gerando o assédio psíquico e físico de vários profissionais envolvidos no ambiente (CAHÚ GRP, et al., 2014).

Os atos de violência mais presentes no ambiente da enfermagem ainda são bem diversificados e englobam agressões verbais, assédio moral, competição entre colegas, agressões físicas, roubos, discriminações sociais e maus trato. Tais atos ainda não representam dados concretos de modificação na atenção à essas ocorrências, assim, vário indivíduos acabam interpretando a situação como algo "normal" e que pode gerar seu afastamento do emprego e/ou distanciamento dos outros profissionais ali presentes, dessa forma, o trabalhador exerce cada vez mais suas características subjetivas levando o mesmo ao estresse ocupacional (CEZAR ES e MARZIALE MHP, 2006).

. Muitas vezes os trabalhadores fingem que nada acontece e acabam ficando expostos a mais atos de assédio e outras formas de violência, por se tratar de uma dinâmica que o próprio profissional, muitas vezes, não consegue modificar. São necessárias estratégias com o intuito de reduzir os casos tão presentes de abusos no âmbito da enfermagem (LIMA GHA e SOUSA SMA, 2015).

O trabalho é uma iteração entre o homem e a natureza e deve ocorrer de maneira harmoniosa, onde ambos possam ser favorecidos, mas esse conceito nem sempre é real e muitas vezes os próprios gestores ficam fixos em um cenário de comodismo, onde pouco é feito para modificar atos de violência e assédio, por exemplo (LIMA GHA e SOUSA SMA, 2015).

O assédio moral na área da saúde pode ser presente de várias formas, mas costuma ser inserida, por exemplo, em casos de impedimento de crescimento profissional, excesso de atividades desnecessárias, violência verbal, ameaça de agressões físicas e até mesmo agressões físicas diretas, sendo que a maioria dos comportamentos entre o agressor e o agredido se torna mais exposto com o tempo, como: o fato do assediador ignorar a presença do assediado frente outras pessoas, interrupções na fala, isolamento em relação aos outros colegas e até proibição de se comunicar com outros profissionais do meio (CAHÚ GRP, et al., 2014). 
No atual cenário brasileiro, o assédio moral tem preocupado autoridades em saúde e que envolvem a justiça do trabalho, mas ainda é necessário o desenvolvimento de políticas públicas que possam reduzir os impactos de tal assédio na sociedade, visto que as consequências e tal ato são imensuráveis e acabam influenciando a vida não apenas de um individuo, mas, muitas vezes, de um grupo familiar. Assim, pode-se confirmar que o assédio moral apresenta uma transcendência significativa na sociedade brasileira e mundial (LIMA GHA e SOUSA SMA, 2015).

Por vezes, o assédio moral engloba atos bem maiores que apenas a agressão verbal e acaba levando reações negativas nos diversos ambientes da vida do trabalhador, tanto social quanto familiar, a hierarquia dos meios produtivos ainda se relaciona diretamente com os casos de violência e precisa ser constantemente avaliado com a finalidade de promover um convívio de trabalho respeitoso e agradável (ANDRADE CG, et al., 2015).

O impacto dos eventos estressores na vida dos indivíduos pode estar relacionado tanto a modificação da estrutura emocional quanto do funcionamento do sistema nervoso central, a identificação dos transtornos de ansiedade na sociedade em geral, e pertinentemente, no ambiente marcado pela força produtiva podem representar a transformação dos ambientes de adoecimento e valorização da saúde biológica, social e mental dos trabalhadores (POLIPPO PM, FERREIRA VRT e WAGNER MF, 2016).

Entre as consequências psicológicas mais comumente observadas em um enfermeiro(a) que sofre de assédio moral, pode-se destacar a presença de memórias perturbadoras relacionada ao/aos momento(os) de agressão, a presença da ansiedade com a possível repetição do ato e o desprazer em realizar as atividades laborais de costumes (XAVIER ACH, et al., 2008). A denúncia e a documentação dos atos de assédio moral ainda constituem a principal maneira de prevenção desses atos de violência (LISBOA MTL, 2010).

Além das diversas consequências comportamentais causadas pelo assédio moral, o suicídio também se mostra presente em muitos casos e, assim, percebe-se que a magnitude das relações de trabalho deve ser um ponto de estudo continuo e frequente para que a redução dos casos de assédio possa ocorrer e que as consequências do mesmo possam ser mais leves e receber a atenção desejada a cada indivíduo (ELOISE MLG, et al., 2012).

As características individuais de cada trabalhador estão relacionadas às habilidades interpessoais e até as condições subjetivas, como afeto e autoestima, e são características que poderão possibilitar a melhor capacidade de adaptação para o enfrentamento do estresse e de outros problemas relacionados, dessa forma, torna-se possível valorizar e incentivar recursos e ferramentas que possam levar em consideração a vivência do indivíduo, as relações interpessoais e até os medos antecipados que o mesmo vive no ambiente de trabalho, pois assim é possível reconhecer precocemente as fragilidades de cada trabalhador em determinado ambiente da instituição bancária (SCHNEIDER AMA, WERLANG BSG e KRISTENSEN CH, 2013).

Embora o assédio moral ocorra de maneira silenciosa na maioria das vezes, profissionais e gestores devem ser cada vez mais atentos em relação aos meios produtivos com o intuito de observarem previamente as situações que possam envolver esse tipo de violência, pois quando se identifica e modifica precocemente qualquer princípio de agressão também se evita problemas futuros mais graves como até mesmo a depressão e reações psicossomáticas (ELOISE MLG, et al., 2012).

Mesmo as organizações tendo um papel fundamental na proteção e bem-estar dos funcionários, ainda são possíveis observa uma diversidade de histórias e vivências que demonstram a necessidade de estudos e pesquisas para a mudança desse paradigma de violência, assim, são necessários investimentos que possam entender a nova dinâmica do trabalho, principalmente, a força trabalhista e os meios produtivos, onde $O$ assédio não possa mais alcançar posições importantes e não represente limitações tão circunstanciais no exercício do trabalho (FONTES KB, PELLOSO SM e CARVALHO MDB, 2011).

O ambiente de trabalho é uma área dinâmica que precisa ser observado para que não se torne um local de adoecimento, dessa maneira, é necessário que o exista o acompanhamento dos indivíduos dentro de

REAEnf/EJNC | Vol. 3 | e2742 | DOI: https://doi.org/10.25248/REAenf.e2742.2020 Página 7 de 9 
suas características, não apenas biológicas, mas principalmente sociais e mentais e que possam ocorrer constantemente e não apenas à exposição a ações de traumas diretos. Além de fatores de violência de exposição direta, a própria precariedade das relações de trabalho assim como a intensificação do ritmo de trabalho leva um indivíduo a diversos transtornos de ansiedade (MEDEIROS GF, et al, 2017).

O assédio moral ainda é uma forma de violência presente dentro dos hospitais onde ocorre, principalmente, com os próprios funcionários da instituição o que gera marcas traumáticas, muitas vezes, para o resto da vida no convívio do ambiente de trabalho e na percepção do indivíduo nas relações interpessoais Tais fatores estão relacionados a uma constante insegurança e estresse dentro das diversas instituições do cuidar não só nacionais, mas até mesmo internacionais (DONAT JC, et al, 2017).

A relação estabelecida entre o enfermeiro e o hospital é tão intensa e ativa que se mistura à vida privada, criando um espaço de dedicação incondicional ao trabalho. Essa fusão entre a vida pública e a vida privada acaba transformando a percepção do trabalhador em vários aspectos e, dessa forma, acaba disseminando os sinais e sintomas de ansiedade, por exemplo, nos diversos segmentos sociais do mesmo, como trabalho e família. É nesse momento que muitas vezes se deparam com questões pessoais que antes não eram percebidas.

Observa-se, portanto, que a organização social do trabalho pode significar não apenas um lugar melhor para exercer sua força de trabalho, mas o equilíbrio necessário para todas as suas relações interpessoais que possa visar a saúde de maneira holística, onde o indivíduo possa ser assistido de maneira biológica, social e mental, e que suas características subjetivas possam se sobrepor em relação ao antigo conceito de "homem como apenas uma ferramenta de trabalho".

\section{CONSIDERAÇÕES FINAIS}

A violência no ambiente laboral é tão antiga quanto à origem do trabalho, mas foi apenas nas últimas décadas que o termo assédio moral começou a ser mais evidente e valorizado no contexto que envolve os trabalhadores nos diversos setores produtivos. O assédio moral é um problema multifatorial que pode afetar características tanto físicas quanto psicológicas e social, e por tal importância, as fiscalizações e avaliações constantes dos ambientes de trabalho ainda são meios importantes de prevenção desse agravo.

\section{REFERÊNCIAS}

1. ANDRADE CG, et al. Assédio moral na atenção básica segundo os profissionais de enfermagem. Trabalho, Educação e Saúde. 2015; 13(Suppl. 1): 77-90.

2. BOBROFF MCC, Martins JT. Assédio moral, ética e sofrimento no trabalho. Rev. Bioét. 2013; 21(2): $251-258$.

3. CAHÚ GRP, et al. Situações de assédio moral vivenciadas por enfermeiros no ambiente de trabalho. Acta paul. enferm. 2014; 27(2): 151-156.

4. CEZAR ES, Marziale MHP. Problemas de violência ocupacional em um serviço de urgência hospitalar da Cidade de Londrina, Paraná, Brasil. Cad. Saúde Pública. 2006; 22(1): 217-221.

5. COSTA ICP, et al. Produção científica acerca de assédio moral em dissertações e teses no cenário brasileiro. Rev. esc. enferm. 2015; 49(2): 267-276.

6. DONAT JC, et al. Terapia de Exposição com Realidade Virtual para Transtorno de Estresse Pós-Traumático para bancários: um estudo de caso com o banco virtual. Contextos Clínicos, 2017; 10(1): 23-32.

7. ELOISE MLG, et al. Assédio moral: compreensão de estudantes de enfermagem. Rev. enferm. UERJ, Rio de Janeiro. 2012; 20(2):161-6.

8. FONTES KB, Pelloso SM, Carvalho MDB. Tendência dos estudos sobre assédio moral e trabalhadores de enfermagem. Rev. Gaúcha Enferm. 2011; 32(4): 815-822.

9. LIMA GHA, Sousa SMA. Violência psicológica no trabalho da enfermagem. Rev. Bras. Enferm. 2015; 68(5): 817823.

10. MARCIA TLL. Assédio moral no trabalho de enfermagem. Cogitare Enferm. 2010; 15(1):9-11.

11. MARGARIDA B, Roberto H. Violência, saúde e trabalho: a intolerância e o assédio moral nas relações laborais. Serv. Soc. Soc. 2015; 123: 544-561.

12. MEDEIROS GF, et al. Sequestros De Bancários E Seus Impactos Psicossociais Na Saúde Do Trabalhador. Rev Bras Med Trab. 2017; 15(1): 42-53.

13. POLIPPO PM, FERREIRA VRT e WAGNER MF. Produção científica brasileira sobre psicologia evolucionista. Gerais, Rev. Interinst. Psicol, Juiz de fora, 2016; 9(2): 277-289. 
14. SANTOS SIL, et al. Assédio moral no âmbito da enfermagem: revisão integrativa da literatura. Cogitare enferm. 2014; 19(1):159-165.

15. SCHLINDWEIN VLDC. Histórias de vida marcadas por humilhação, assédio moral e adoecimento no trabalho. Psicologia \& Sociedade. 2013; 25(2): 430-439.

16. SCHNEIDER AMA, WERLANG BSG, KRISTENSEN CH. Características de personalidade em bancários vítimas de assalto no local de trabalho. Psic., Saúde \& Doenças, Lisboa, 2013; 14(1): 125-140.

17. SILVA OD, Raichelis R. O assédio moral nas relações de trabalho do(a) assistente social: uma questão emergente. Serviço Social \& Sociedade. 2015; (123): 582-603.

18. XAVIER ACH, et al. Assédio moral no trabalho no setor saúde no Rio de Janeiro: algumas características. Rev. bras. saúde ocup. 2008; 33(117): 15-22. 